\title{
As lições de Perseu Abramo sobre a manipulação na imprensa
}

\author{
Tânia Regina de Faveri Giusti \\ Samuel Pantoja Lima²
}

\section{Resumo}

Este trabalho tem como objetivo ressaltar a aplicabilidade e a contribuição da obra de Perseu Abramo para a Teoria do Jornalismo. O texto apresenta conceitos e quatro práticas de manipulação observadas, identificadas e classificadas pelo autor. Foi utilizada como metodologia a pesquisa bibliográfica. Mais de 20 anos após o lançamento da obra, os estudos realizados pelo professor permanecem atuais, fornecendo um instrumental precioso para a compreensão e crítica do fazer jornalístico brasileiro, principalmente em tempos de ruptura democrática.

Palavras-chave: Jornalismo; Manipulação; Poder; Perseu Abramo.

\section{Abstract}

This work aims to highlight the applicability and contribution of the work of Perseus Abramo for Journalism Theory. The text presents concepts and four manipulation practices observed, identified and classified by the author. Bibliographic research was used as methodology. More than 20 years after the launch of the work, the studies carried out by the professor remain current, providing a valuable tool for understanding and criticizing Brazilian journalistic work, especially in times of democratic rupture.

Keywords: Journalism; Manipulation; Power; Perseu Abramo.

\footnotetext{
I Mestranda do programa de pós-graduação em jornalismo da UFSC. Jornalista graduada em Comunicação Social - Jornalismo pela Faculdade Satc, de Criciúma. E-mail: taniargiusti@gmail.com

2 Docente e pesquisador do curso de Jornalismo da UFSC. Atualmente participa da coordenação da pesquisa "Governança Social, Produção e Sustentabilidade para um jornalismo de novo tipo (GPS-JOR)". E-mail: samuca13@gmail.com
} 


\section{Introdução}

Mais de 20 anos se passaram desde que o jornalista e sociólogo Perseu Abramo escreveu sua única obra, Padrões de manipulação na grande imprensa. No entanto, os padrões de manipulação observados, identificados e classificados pelo estudioso na década de 1980 são indispensáveis, e continuam sendo aplicados para ler e compreender o poder da mídia nos dias atuais.

Perseu Abramo nasceu em 1929, em São Paulo. Em 1959, formou-se em Ciências Sociais pela Faculdade de Filosofia, Ciências e Letras da Universidade de São Paulo (USP). Em 1968, cursou mestrado em Ciências Humanas na Universidade Federal da Bahia (UFBA). Cedo iniciou suas atividades no jornalismo. Trabalhou na Folha, no jornal O Estado de S. Paulo, na Abril Cultural, na Rede Globo e em órgãos da imprensa partidária. Trabalhou 15 anos na Pontifícia Universidade Católica de São Paulo (PUC-SP), de 1981 até sua morte em 1996, aos 66 anos, decorrente de uma embolia pulmonar.

Era filiado ao Partido dos Trabalhadores (PT), partido que ajudou a construir, e pertencia ao Diretório e à Executiva Nacional da sigla, onde ocupava a Secretaria de Formação Política. Abramo também lecionou na Escola de Jornalismo Casper Líbero (1960-1962) e participou da implantação do Departamento de Ciências Humanas (19621964) da Universidade de Brasília (UnB). Participou a partir de 1977 do CBA (Comitê Brasil Anistia) e, entre 1989 e 1990, foi secretário de imprensa da Prefeitura de São Paulo, na gestão de Luiza Erundina.

No campo sindical ${ }^{3}$, fez parte de comissões universitárias de solidariedade a operários em greve. Teve atuação importante na formação da Comissão de Liberdade de Imprensa do Sindicato e na preparação das teses que foram debatidas e aprovadas no Congresso de Liberdade de Imprensa, passos importantes da categoria para combater a censura da ditadura e elevar o grau de conscientização e politização dos jornalistas e dos trabalhadores em geral. Participou ativamente da greve da categoria em 1979, onde atuou no comando geral. Foi um dos idealizadores do Prêmio Vladimir Herzog de Anistia e Direitos Humanos, criado pelo Sindicato dos Jornalistas de São Paulo.

Em 1996, após sua morte, o Diretório Nacional do Partido do Trabalhadores instituiu a Fundação Perseu Abramo, projeto que Perseu ajudou a organizar antes de falecer. O objetivo do órgão era: 
[...]constituir um espaço, fora das instâncias partidárias, para desenvolvimento de atividade de reflexão política e ideológica, de promoção de debates, estudos e pesquisas, com a abrangência, a pluralidade de opiniões e a isenção de ideias pré-concebidas que, dificilmente, podem ser encontradas nos embates do dia-a-dia de um partido político. (www.fpabramo.org.br) ${ }^{4}$

Um ano após a criação da entidade, a jornalista Beatriz Abramo, filha de Perseu, organizou a obra Um trabalhador da notícia, a primeira lançada pela Fundação, com textos e artigos opinativos do escritor, publicados ao longo da carreira jornalística.

$\mathrm{Na}$ década de 1980, o jornalista não idealizava o quanto as redes sociais influenciariam na produção, discussão e compartilhamento de conteúdo. As mídias sociais transformaram-se em poderosas fontes de informação, sendo tidas como confiáveis (apesar de todos os problemas e escândalos envolvendo notícias falsas) para muitos brasileiros, é o que mostra o Relatório de Jornalismo Digital 2017, do Instituto Reuters para a Universidde Oxford $^{5}$. A jornalista Patrícia Cornils, que escreveu o texto de apresentação da segunda edição da obra Padrões de Manipulação na grande imprensa, relançado em 2016, afirma que "as plataformas online concederam mais autonomia aos leitores e espectadores. Para ela, jornais e revistas da imprensa tradicional não têm mais o poder quase exclusivo de formar opiniões e são menos incontestáveis, apesar de ainda serem responsáveis pelas notícias mais lidas e compartilhadas" (CORNILS in ABRAMO, p.8).

Com o surgimento de plataformas como o Facebook, a mídia de massa está perdendo, aos poucos, o monopólio da interpretação dos acontecimentos. Este maior engajamento e participação se dá, Segundo Castells (2003), pois as tecnologias em rede da contemporaneidade aboliram distâncias e transformaram a sociedade em um sistema interativo de comunicação local global em tempo real. Apesar da produção descentralizada de notícias, com o advento da internet, a concentração dos meios de

\footnotetext{
${ }^{1}$ Biografia de Perseu Abramo. Disponível em: https://fpabramo.org.br/2010/02/11/sobre-perseu-abramo/ Acesso em: 13 de janeiro de 2018

2 Biografia de Perseu Abramo. Disponível em: https://fpabramo.org.br/2010/02/11/sobre-perseu-abramo/ Acesso em: 13 de janeiro de 2018.
}

5 Digital News Report 2017. Disponível em: http://www.digitalnewsreport.org/survey/2017/overviewkey-findings-2017/ Acesso em: 06/12/2018 
comunicação em poucos grupos de poder ainda é uma realidade, e diante este fato, novas organizações e coletivos passaram a se organizar para fazer uma contranarrativa dos fatos. Este engajamento citado por Castells, pôde ser visto em 2013, quando grupos e coletivos que atuam na chamada mídia contra-hegemônica, começam a ganhar espaço nos feeds brasileiros. Cornils (2016) cita como exemplo a cobertura das manifestações de junho de 2013 no Brasil, onde atores sociais como o Coletivo Mídia Ninja, e o internauta que compartilhou o vídeo de um policial quebrando o vidro da própria viatura, competiram, no Facebook, com as narrativas realizadas pela mídia tradicional. Prevendo um futuro do qual infelizmente não pode participar, em dezembro de 1995, em um discurso para estudantes de jornalismo, o pesquisador já alertava sobre a influências das novas tecnologias na profissão:

O maior desafio desta nossa profissão nos dias de hoje é distância entre a técnica e a ética. Cada vez mais, avançam as novas tecnologias, a informática, a telemática, a transmissão por satélites, ondas hertzianas, fibras óticas, 'estradas eletrônicas', infovias, telefone celular, fax, computador, modem, a Internet e outras redes. E, cada vez mais, o poder político e econômico dos grandes impérios empresariais e multinacionais da comunicação se concentra em um número cada vez menor de poucas mãos (ABRAMO in CORNILS, 2016, p.9).

Para Cornils (2016) com o surgimento das redes sociais, a própria manipulação tornou-se uma linguagem nas redes. As técnicas de manipulação, elencadas por Abramo, são as próprias ferramentas que produzem perfis falsos, textos de origem duvidosa e até os chamados memes. "A compreensão de como essa linguagem se estrutura por tais procedimentos, serve de guia de leitura crítica e imprescindível para entender em que espaço se dá a junção da imprensa e do poder no mundo contemporâneo" (CORNILS in ABRAMO, 2016, p.10).

Para a autora, em tempos de polarização política, a imprensa deveria refletir de forma ainda mais zelosa sobre a realidade, em profundidade e sem deformações. Agindo na contramão da democracia, a mídia não só a enfraquece, como reforça seu papel de "partido", assunto que debateremos ao longo do texto. As consequências de assumir este posicionamento, além dos prejuízos à formação da opinião pública, ainda estão para ser avaliadas em sua amplitude, conclui.

Cabe ressaltar que na época da publicação do livro, o Brasil já vivia no período de abertura democrática e dava os primeiros passos para abraçar as novas tecnologias, mas ainda não contava com internet comercial, considerada hoje como um Revista Pauta Geral-Estudos em Jornalismo, Ponta Grossa v.5, n.2, p.58-74, Jul/Dez 2018. 
espaço de resistência e de "cobrança" de posicionamentos dos públicos para com os profissionais da comunicação. Para Cornils (2016), "parte da disputa pela opinião pública se dá nesta esfera conectada e em publicações online independentes da grande mídia".

Os quatro padrões de manipulação identificados e classificados pelo autor, ocultação, fragmentação, inversão e indução, que serão discorridos e exemplificados no decorrer deste artigo, fornecem um instrumental precioso para a compreensão e crítica do fazer jornalístico brasileiro, principalmente em tempos de crise política e ruptura democrática, convergência midiática e ascensão das redes sociais, que nem sequer existiam na década de 80 .

A partir desta análise, adotou-se como metodologia a revisão bibliográfica, por meio de uma análise comparativa dos padrões elucidados pelo autor, com alguns acontecimentos jornalísticos atuais. A pesquisa bibliográfica contribuiu nas construções teóricas, nas comparações e na validação dos resultados.

\section{A imprensa como partido que sustenta o poder}

"Urgente, luminoso e indispensável". Com esses três adjetivos, o professor da Unicamp e colaborador da Fundação Perseu Abramo Reginaldo de Moraes (2016, p.13) inicia o prefácio de Padrões de manipulação na grande imprensa. Ele destaca que, como partido político, a mídia se tornou um instrumento crítico para coordenar ações políticas. "Ela descreve, contextualiza, dá sentido, mas também julga, orienta o julgamento e a execução dos atos". Na sequência, ele ressalta que a publicação da edição revisada do livro não poderia ter sido realizada em momento mais oportuno, fazendo referência a abril de 2016, no mês da aceitação da denúncia na Câmara, quatro meses antes à decisão que depôs a presidente Dilma Rousseff, por meio de um processo de impeachment. $\mathrm{Na}$ concepção do autor, "o partido da imprensa se tornou o comando supremo do golpe":

[...] a mídia opera como maestro de uma grande orquestração, a orquestração de um golpe do Estado e de uma tentativa de impor um novo regime à jovem democracia brasileira, subordinando o voto a uma espécie de superego oligárquico composto pelo triunvirato judiciáriomidiático-financeiro (MORAES in ABRAMO, 2016, p.13).

O autor ainda objetiva que o ensaio analítico de Abramo é um exercício crítico voltado ao desvendamento de "artimanhas, métodos e recursos do discurso manipulador". Os quatro padrões, que serão descritos no decorrer deste artigo, na opinião de Moraes Revista Pauta Geral-Estudos em Jornalismo, Ponta Grossa v.5, n.2, p.58-74, Jul/Dez 2018. 
(2016, p.14), também podem ser chamados de rotinas lógicas da desrazão, de desconstrução da realidade e da criação de uma nova "supra realidade", que a substitua nos [corações e mentes] dos leitores, ouvintes e telespectadores.

José Arbex Junior, que também colaborou com a reedição da obra de Abramo, e que é professor da PUC de São Paulo e consultor editorial da Revista Caros Amigos, define a mídia como uma coluna de sustentação do poder:

Ela é imprescindível, como fonte legitimadora das medidas políticas anunciadas pelos governantes e das "estratégias de mercado" adotadas pelas grandes corporações e pelo capital financeiro. Constrói consensos, educa percepções, produz realidades parciais apresentadas como totalidade do mundo, mente, distorce os fatos, falsifica, mistifica - atua, enfim, como um "partido" que, proclamando-se porta-voz e espelho dos "interesses gerais" da sociedade civil, defende os interesses específicos de seus proprietários privados (ARBEX in ABRAMO, 2016, p.20).

Para Arbex, Perseu Abramo e o jornalista Aloysio Biondi, que escreveu o pósfacio da obra, fornecem um guia exemplar para quem deseja aprender a ler a mídia. $O$ primeiro analisa a imprensa escrita, a televisão e o rádio; o segundo, a imprensa escrita. Alberx recorda que o texto de Abramo é de 1988, anterior à cobertura da Guerra do Golfo, por exemplo, quando a CNN transmitiu em tempo real as imagens e notícias. Ele salienta que pela primeira vez na história da humanidade, "a tecnologia - e não o homem - foi o centro da cobertura de uma guerra". E foram as constantes evoluções tecnológicas que resultaram em um novo padrão não analisado pelo estudioso: o padrão que permite fabricar socialmente a amnésia, pela velocidade em que as informações são compartilhadas. Mal tomamos conhecimento de um assunto e, em seguida, novas manchetes fazem com que esqueçamos aquilo que segundos atrás era considerado fundamental (ARBEX in ABRAMO, 2016, p.21).

O jornalista e professor universitário Hamilton Octavio de Souza, que foi aluno, colega de trabalho e companheiro de Abramo na organização no PT, salienta que a formação em Sociologia do escritor facilitava o entendimento das técnicas de pesquisa cientifica. Para Souza in Abramo (2016, p.28), "Perseu sabia perfeitamente o que muitos jornalistas e professores de jornalismo não sabem ainda no dia de hoje: que a atividade somente pode ser entendida e analisada como categoria política, como instrumento de propagação ideológica de grupos, setores e classes sociais". Segundo ele, o jornalismo praticado pela imprensa comercial-burguesa o legitima como instrumento de controle político das elites, contrário aos interesses maiores do povo brasileiro. 
No debate sobre a verdadeira motivação da empresa de comunicação em manipular a informação e distorcer a realidade, Perseu coloca o campo econômico, a busca do lucro, num segundo plano, já que esse pode ser obtido com melhor resultado em outras atividades empresarias. Para ele, a motivação real está no campo político, na lógica do poder (SOUZA in ABRAMO, 2016, p.30).

Para Souza, os padrões de manipulação observados podem ser aplicados integralmente na análise dos veículos de comunicação atualmente, tendo em vista que as distorções denunciadas por Perseu continuam dominando as redações, devido à adesão os valores do neoliberalismo nos últimos dez anos, por parte da mídia jornalística.

O título da obra inicialmente seria O significado político de manipulação. Esta ligação com a política se dá, porque a distorção da realidade pela manipulação da informação é deliberada, tem um significado e um propósito. Desde que Perseu escreveu sua obra, até os dias de hoje (maio de 2018), os principais órgãos de comunicação do Brasil continuam sendo de propriedade privada. Do ponto de vista econômico, o autor esclarece:

A primeira questão desloca para a figura do anunciante a responsabilidade última e maior pelo produto final da comunicação: por imposição, de anunciantes privados ou estatais que o empresário se vê obrigado a manipular e distorcer. A segunda diz respeito a ambição de lucro do próprio empresário de comunicação, mas a motivação é econômica (SOUZA in ABRAMO, 2016, p.59).

É evidente que os órgãos de comunicação e a indústria cultural de que fazem parte estão submetidos à lógica econômica do capitalismo. Mas o capitalismo opera também com outra lógica, a lógica política, do poder, onde é possível encontrar a explicação da manipulação jornalística (SOUZA in ABRAMO, 2016, p. 60). Na hipótese de trabalho de Perseu, os meios de comunicação se tornam novos órgãos de poder, de caráter político-partidário, e por isso precisam recriar a realidade onde exercer esse poder, e para recriá-la, precisam manipular as informações.

A manipulação, assim, torna-se uma necessidade da empresa de comunicação, mas como a empresa não foi criada nem organizada para exercer diretamente o poder, ela procura transformar-se em partido político. Aliás, os grandes e modernos órgãos de comunicação, no Brasil, parecem-se efetivamente com partidos políticos (SOUZA in ABRAMO, 2016, p.61).

Ele então enumera algumas dessas semelhanças: a)partidos têm seus manifestos de fundação, os órgãos de comunicação têm suas linhas editoriais; b) Partidos 2018. 
têm estatutos, órgãos têm manuais de redação; c) os partidos têm filiados, e os órgãos têm seus empregados; d) os partidos têm representatividade, já os meios de comunicação agem como se também recebessem mandatos de representação popular: "oscilam entre se auto suprirem demiurgos da vontade divina ou mandatários do povo, e confundem o consumo dos seus produtos ou o índice de tiragem ou audiência com o voto popular depositado em urna" (ABRAMO, 2016, p. 63).

\section{O culto ao oficialismo e os prejuízos à democracia}

Um dos exemplos de manipulação explicados por Aloysio Biondi refere-se ao oficialismo, uma das questões mais presentes nos textos do final dos anos 1980 e início dos anos 1990. Souza recorda que, nos governos de Fernando Henrique Cardoso (1994 a 2002), os veículos foram transformados em reprodutores e retransmissores do discurso oficial e, inclusive, replicaram as manipulações forjadas nos palácios de Brasília.

À medida que "o oficialismo atinge a grande maioria da atividade jornalística, em que a diversidade e a pluralidade de informações e opiniões deixam de ter o seu espaço na sociedade, ele se transforma em autoritarismo", afirma Abramo em seus textos, com tremenda percepção do que aconteceria nos anos seguintes na imprensa brasileira (SOUZA in ABRAMO, 2016, p.31).

Passam-se os anos e o culto ao oficialismo continua sendo difundido nas redações Brasil afora. No Governo FHC, o "Milagre Econômico" do Plano Real e ações como as privatizações, ganharam espaços e manchetes de destaque, atendendo fielmente o que os gabinetes do presidente solicitavam.

Souza recorda da edição de 30 de junho de 1998, do Jornal O Estado de São Paulo, quando o meio de comunicação, empenhado na reeleição de FHC, apresentou chamadas na capa com previsões do futuro, como "privatização das teles criará dois milhões de empregos", ou "governo abrirá financiamento da casa própria", sendo que as chamadas dos jornais jamais se concretizaram na época, e as matérias não tinham nenhuma relação com os fatos reais, apenas com intenções e declarações de pessoas envolvidas com o governo.

Para o autor, os padrões de manipulação e uma análise crítica da mídia são ignorados pelas escolas "afundadas nas teorias que cuidam da aparência, do visual, da 
imagem e do signo". Com base no padrão de inversão, e no que tange a descrição da linguagem na descrição de um fato, o pesquisador afirma:

O texto passa a ser mais importante que o fato que ele reproduz; a palavra, a frase, no lugar da informação; o tempo e o espaço de cada matéria predominando sobre a clareza da explicação; o visual harmônico sobre a veracidade ou a fidelidade; o ficcional espetaculoso sobre a realidade (ABRAMO, 2016, p.33).

A distorção da realidade, ou a criação ficcional de espetáculos, são praticados diariamente, às vezes de maneira sutil, em outras de forma escancarada e agressiva na mídia jornalística.

\section{Significado político e os quatro padrões de manipulação}

Abramo (2016, p.33), no texto originalmente escrito em 1988, enfatiza que muitos meios de comunicação elaboram e oferecem materiais criados a partir de uma realidade artificial, apresentada no lugar da realidade real, "uma relação indireta da realidade". As informações manipuladas que compõem essa cobertura "não real" são lançadas à opinião pública, se superpondo e dominando a realidade real que os leitores ou telespectadores vivem e conhecem. Infelizmente, o receptor só perceberá as contradições quando esta matéria, televisionada, narrada ou escrita, refletir uma parcela de realidade da qual ele é protagonista ou testemunha.

\footnotetext{
A imensa parte da realidade ele a capta por meio da imagem artificial e irreal da realidade criada pela imprensa; essa é, justamente, a parte da realidade que ele não percebe diretamente, mas aprende por conhecimento. Daí que cada leitor tem, para si, uma imagem da realidade que na sua quase totalidade não é real. É diferente $e$ até antagonicamente oposta à realidade. A maior parte do indivíduo portanto, move-se num mundo que não existe, e que foi artificialmente criado para ele justamente a fim de que ele se mova nesse mundo irreal. Manipulação das informações se transforma, assim, em manipulação da realidade (ABRAMO, 2016, p.39).
}

Abramo tipificou as formas mais usuais de manipulação, classificando-as como padrões observáveis na produção jornalística. São quatro padrões gerais para a imprensa e um específico ao telejornalismo. O primeiro deles é o padrão de ocultação, que é "o padrão que se refere à ausência e à presença dos fatos reais na produção da imprensa. Não por desconhecimento ou omissão diante do real, mas por um deliberado silêncio militante sobre determinados fatos da realidade" (ABRAMO, 2016, p.38). Segundo

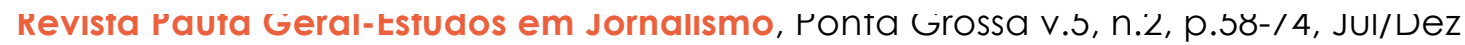
2018. 
o autor, este padrão opera durante o momento da busca pela informação e do planejamento da edição da programação ou matéria.

A ocultação do real está ligada diretamente aos fatos jornalísticos. Para o autor, existe uma concepção predominante entre empresários e empregados dos órgãos de comunicação sobre "fatos jornalísticos" e "não-jornalísticos". E que o papel de selecionar o que será notícia, ou seja, que se tornará um fato, é do jornalista. Na prática, essa concepção já atua na manipulação do real. Quaisquer que sejam as características jornalísticas, "não residem no objeto da observação, e sim no sujeito, na relação que este estabelece com aquele".

O 'jornalístico' não é uma característica intrínseca do real em si, mas da relação que o jornalista, ou melhor, órgão de jornalismo, a imprensa, decide estabelecer como realidade. Nesse sentido, todos os fatos, toda a realidade pode ser jornalística, e o que vai tornar jornalístico um fato independe das suas características reais intrínsecas, mas depende, sim, das características do órgão de imprensa, da sua visão de mundo, da sua linha editorial, do seu 'projeto' (ABRAMO, 2016, p. 41).

Abramo (2016, p. 40) ressalta que o padrão de ocultação é decisivo e definitivo na manipulação da realidade. "Tomada a decisão de quem um fato "não é jornalístico", não há a menor chance de que o leitor tome conhecimento de sua existência, por meio da imprensa". Dessa forma, o fato real é eliminado da realidade, e por estar ausente deixa de ser real e torna-se imaginário. Já o fato presente na produção jornalística, real ou ficcional, passa a tomar o lugar do faro real, e a compor uma realidade artificial.

Se, no padrão anterior, os jornalistas definem o que é fato jornalístico e o que não é, no padrão de fragmentação, o segundo estudado por Abramo, todo o "resto" de realidade é apresentado ao leitor não como uma realidade, com todo o seu enredo (movimentos, estruturas, causas, condições e consequências).

O todo real é estilhaçado, despedaçado, fragmentado em milhões de minúsculos fatos particularizados, na maior parte dos casos desconectados entre si, despojados de seus vínculos com o geral, desligados de seus antecedentes e de seus consequentes no processo em que ocorrem, ou reconectados e revinculados de forma arbitrária e que não correspondem aos vínculos reais, mas a outros ficcionais, e artificialmente inventados. Esse padrão também se operacionaliza no "momento" do planejamento da pauta, mas, principalmente no da busca da informação, na elaboração do texto, das imagens e sons, e no de sua apresentação, na edição (ABRAMO, 2016, p.42). 
Pereira Filho (2009) concorda com a avaliação de Perseu, e utiliza as citações do colega em seu livro para reforçar a questão. Para ele, a "mesmice" de temas, assuntos e enfoques encontrada na grande imprensa e o reducionismo de linguagem que ela adota não são obras do acaso ou do inevitável. "Elas fazem parte de uma montada estrutura empresarial, administrativa e de poder, somada a um sistema de valores e interesses, que cria os mecanismos internos (editores, manuais, regras de linguagem, repórteres passivos), para vender à opinião pública a mercadoria notícia, com seus vieses e leituras de mundo[...]" (PEREIRA FILHO, 2009, p. 23).

Esses mecanismos internos fazem parte das duas operações básicas: a seleção de aspectos, ou particularidades do fato e a descontextualização. Os critérios para essa seleção não residem necessariamente na natureza os nas características do fato decomposto, mas nas decisões, na linha, no projeto do órgão de imprensa, e que são transmitidos, impostos ou adotados pelos jornalistas desse órgão. Já na descontextualização, determinação de fatos, informações ou declarações perdem o significado original e real, recebendo um significado diferente. A junção de todos estes elementos colabora para a distorção da realidade e a criação artificial de uma outra realidade.

O terceiro padrão é o da inversão, que é o reordenamento das partes de um fato, substituições, troca de lugares e importância dessa parte. Segundo o autor, é um padrão que "opera tanto no planejamento quanto na coleta e transcrição das informações, mas que tem seu reinado por excelência, no momento da preparação e da apresentação final, ou da edição de cada matéria ou de conjunto de matérias" (ABRAMO,2016 p. 43).

O autor aponta várias formas de inversão: a de relevância de aspectos, inversão da forma pelo conteúdo, inversão da versão pelo fato, e a inversão da opinião pela informação. Na inversão da relevância de aspectos, "o secundário é apresentado como principal; o particular pelo geral e vice-versa; o acessório e supérfluo no lugar do importante e decisivo, etc". Na inversão da forma pelo conteúdo, "o texto passa a ter mais importância do que o que ele reproduz, o ficcional espetaculoso predomina sobre a realidade"; Na Inversão da versão pelo fato "não é o fato em si que passa a importar, mas a versão que dele tem o órgão de imprensa, seja essa versão originária do próprio órgão de imprensa, seja adotada ou aceita de alguém [...]". Este padrão, junto das demais formas de manipulação, ocorre por meio do frasismo, que é "quando uma frase, um trecho, 
uma expressão ou uma palavra, são apresentadas como a realidade original"(ABRAMO, 2016, p.45).

Outro apontamento registrado por Abramo (2016) dentro da inversão, é o oficialismo, "expressão utilizada para indicar a fonte oficial de qualquer segmento da sociedade, sendo que no lugar dos fatos é dado preferência a esta versão oficial, sendo considerada superior à do próprio órgão de imprensa"(ABRAMO, 2016, p.46).

Nem sempre as versões oficiais são as mais adequadas, justas ou verdadeiras. Muitos veículos estão reféns das fontes oficias, e os resultados são nocivos para a opinião pública, como mencionado por Abramo: "As versões das autoridades, valem muito mais do que a dos personagens que não detém autoridade, e valem mais até que a própria realidade, transformando o oficialismo em autoritarismo" (ABRAMO, 2016, p.46). Em 2017, as versões oficiais fizeram boa parte da imprensa brasileira pré-julgar o reitor da Universidade Federal de Santa Catarina, Luiz Carlos Cancellier ${ }^{6}$. Neste caso, escreveu o jornalista Lércio Portela, em reportagem especial pra o Marco Zero ${ }^{7}$, em 2016, com imagens e textos exemplificando todos os padrões de manipulação determinados por Abramo (2016):

Costumamos falar na judicialização da política, mas na verdade o que existe hoje no país é a judicialização do jornalismo, que diariamente aponta o dedo e dá sua sentença sobre quem é e quem não é bandido. Quem pode e quem não pode ter acesso à plena liberdade de expressão. Neste tribunal-noticiário falam primeiro as autoridades policiais e judiciais, depois os jurados da oposição e, em seguida, perto do final do julgamento-matéria, os reús e suas breves notas de repúdio. Mas a sentença quem determina é a grande mídia, em forma de editorial, como o jornal Estado de São Paulo fez recentemente - pedindo um Basta! e insuflando o impeachment - ou como a Revista Veja faz desde sempre.

\footnotetext{
${ }^{6} \mathrm{Na}$ investigação sobre um possível desvio em verbas da Educação à Distância na Universidade, Cancellier foi denunciado por estar "obstruindo as investigações", acusação negada pelo professor em vida. A mídia, na época, em quase sua totalidade, estampou grandes manchetes, e reproduziu de forma leviana o que ouviu das fontes oficiais em uma coletiva de imprensa realizada em Florianópolis, e teve parcela significativa no linchamento moral do qual o professor foi submetido antes de suicidar-se. Em maio de 2018, o inquérito de 817 páginas sobre a Operação Ouvidos Moucos foi finalizo e a Polícia Federal não soube dizer como o reitor se beneficiou, muito menos apresentou provas dos supostos crimes.
}

${ }^{7}$ Padrões de manipulação na grande imprensa, um manual para tempos de crise. Disponível em: https://marcozero.org/padroes-de-manipulacao-na-grande-imprensa-um-manual-paratempos-de-crise/ 
O último item dentro deste último padrão é a Inversão da opinião pela informação. Esse processo seria na verdade o resultado da utilização sistemática e abusiva de todos esses padrões de manipulação que leva quase inevitavelmente a outro padrão: o de substituir, inteira ou parcialmente, a informação pela opinião". O grande agravante desta escolha, para Abramo, é que "o órgão de imprensa apresenta a opinião no lugar da informação, com a agravante de faze-la passar pela informação"(ABRAMO, 2016, p.47).

O gênero opinativo, seja por meio de editorial ou comentário, no caso da tevê, junto às coberturas, completavam-se entre si e ofereciam ao leitor alternativas para ele formar sua opinião, no gênero informativo, de forma independente. No entanto, não é o que acontece:

Hoje, exatamente ao contrário, o fato é apresentado ao leitor arbitrariamente escolhido dentro da realidade, fragmentado no seu interior, com seus aspectos correspondentes selecionados e descontextualizados, reordenados invertidamente quanto a sua relevância, seu papel e seu significado e, ainda mais, tendo suas partes reais substituídas por versões opiniáticas dessa mesma realidade. O jornalismo, assim, não reflete nem a realidade nem essa especifica parte da realidade que é a opinião pública ou do seu público (ABRAMO, 2016, p.47).

Por último, dentro das mídias impressas, há o padrão de indução, "resultado e ao mesmo tempo o impulso final da articulação combinada de outros padrões de manipulação dos vários órgãos de comunicação com os quais ele tem contato" (ABRAMO 2016, p. 48). Indução desta realidade, é responsabilidade de todo o conjunto da imprensa, mas os que devem ser responsabilizados de forma mais efetiva, na visão do autor, são os maiores meios de comunicação, ou seja, os mais "poderosos, "os que tem maior tiragem e audiência, e que ocupam maiores espaços, e que veiculam mais publicidade" (ABRAMO, 2016, p.49).

Ela pode ser manifestada pelo "reordenamento ou recontextualização dos fragmentos da realidade, subtexto (aquilo que é dito sem ser falado), da diagramação e da programação, das manchetes, notícias e comentários, sons e imagens, pela presença/ausência de temas, segmentos do real, de grupos da sociedade e de personagens" (ABRAMO, 2016, p.49).

Abramo elencou um padrão específico para o jornalismo de televisão e rádio, que também pode ser chamado de padrão global (expressão para algo completo/problema e solução). Este padrão se divide em três momentos básicos, "como e fossem três atos de Revista Pauta Geral-Estudos em Jornalismo, Ponta Grossa v.5, n.2, p.58-74, Jul/Dez 2018. 
um espetáculo", como define o autor. O primeiro é o da exposição ao fato, "que é apresentado sob os seus ângulos menos racionais e mais emocionais, espetaculares e mais sensacionalistas". Essa exposição de determinadas situações (assalto, crime, greve, passeata, convenção do partido), é amparada por textos lidos ou falados. O segundo momento é o da "sociedade fala", quando imagens e sons apresentam seus "testemunhos, suas dores e alegrias, apoios e críticas, queixas e propostas". Já o terceiro momento, ou terceiro ato, é o da "autoridade resolve", que é "quando a autoridade anuncia as providências, as soluções já tomadas". Quanto à cobertura de fatos sociais (greve, passeata, sessões parlamentares), "a autoridade reprime o mal e enaltece o bem, e também anuncia as soluções já tomadas ou a tomar, para as duas situações". "Nos dois casos, a autoridade tranquiliza o povo, desestimula qualquer ação autônoma e independente do povo, mantém a autoridade e a ordem, submete o povo ao controle dela, autoridade" (ABRAMO, 1988, pg. 52). Após este momento ("autoridade resolve"), a própria emissora, por meio do apresentador ou comentarista que contesta ou substitui, caso não esteja de acordo com os princípios da empresa, ou reforça o papel alienante da autoridade.

Perseu coloca que são as "retenções das imagens finais da notícia no telejornalismo que subsistirão no telespectador, com a mensagem essencial da matéria, individualizada nas imagens iniciais. E, assim, o padrão de indução da outra realidade se completa e se reforça com o poderoso instrumento do radiojornalismo e do telejornalismo. " (ABRAMO, 1988, pg.52).

\section{Considerações finais}

Nas reflexões geradas a partir dos quatro padrões e seus desdobramentos, Perseu destaca que é impossível buscar um jornalismo "livre" de manipulação sem fazer o debate sobre objetividade e subjetividade. Ele ressalta que há diferenças fundamentais entre a objetividade e os demais conceitos.

O autor ainda afirma que o jornalismo trata do mundo real, do "natural" ou "histórico", e que esse mundo real é repleto de contradições reais, conflitos, antagonismos e de lutas, e questiona sobre o que significa realmente ser neutro, imparcial ou isento?" Neutro a favor de quem, num conflito de classes? "Imparcial" contra quem, diante de uma 
greve, da votação de uma Constituição? "Isento" para que lado, num desastre atômico ou num escândalo administrativo"? (ABRAMO, 1988, p. 54).

Partindo desse pressuposto, Abramo coloca que o jornalismo deve ser nãoneutro, não-imparcial e não isento diante dos fatos da realidade. Ele ainda acrescenta que "o órgão de comunicação não apenas pode mas deve orientar seus leitores/espectadores, a sociedade, na formação da opinião, na tomada de posição e na ação concreta enquanto seres humanos e cidadãos".

Ele também reforça que, a objetividade faz parte do campo do conhecimento, sendo uma categoria ligada ao conhecimento humano, e que tem a ver com a relação que se estabelece entre o sujeito observador e o objeto observável. Portanto, a objetividade é uma característica da observação, do conhecimento, do pensamento. Ele ainda reforça que, durante muito tempo, uma falsa objetividade percorreu muitos manuais de redações de alguns veículos, porém, falsa porque restringe-se a aspectos aparentes e quantificáveis, e as realidades não são redutíveis à números, cifras, pesos e metros.

Para impedir esses erros e impedir a manipulação deliberada da realidade, o autor recomenda que os jornalistas busquem chegar sempre ao mais próximo dela. Acrescenta que "é fundamental separar e distinguir informação de opinião, indicar as diferenças de conteúdo e forma dos gêneros jornalísticos, e apresentar toda a produção jornalística ao leitor/telespectador de forma a que ele perceba imediatamente o que é a exposição da realidade, e o que é ajuizamento de valor" (ABRAMO, 1988, p. 58).

O estudioso ainda enfatiza na obra que as transformações pelas quais 0 jornalismo anseia iniciarão pelos conflitos internos das redações, pela luta sindical e pela prática do dia a dia. Aliado aos próprios profissionais de comunicação, estaria então o povo:

Às classes dominadas caberá o papel fundamental das transformações na visão do jornalismo pela população. [..] não mais terão motivos para acreditar na imprensa ou seguir as suas orientações, passarão a intensificar sua postura crítica, sua análise de conteúdo e forma, diante dos órgãos de comunicação. Por meio de seus setores mais organizados, as classes dominadas contestarão as informações jornalísticas, farão a comparação militante entre o real acontecido e o irreal comunicado, farão a denúncia sistemática da manipulação e da distorção (ABRAMO, 1988, p.67).

Mais de 20 anos depois, as contribuições de Perseu Abramo não perderam o vigor, nem a relevância. Em tempos de convergência de mídia e ruptura democrática, o 
debate sobre as suas contribuições para a manutenção da democracia- na tríade mídia, estado e poder- continua sendo urgente e necessário. Proporcionar este ambiente crítico e reflexivo e delegar aos jornalistas o papel de guardiões da democracia, foram as grandes contribuições do escritor para a teoria do jornalismo. Porém, é preciso ir além. $O$ jornalismo, depois de tantos anos sob a regência de diferentes formas de manipulação entrou em uma crise financeira. A questão central era responder como os modelos de negócio se manteriam diante da queda das receitas publicitárias. No jornalismo pósindustrial, período que vivemos atualmente, a mídia segue se reiventando e buscando formas de se manter financeiramente.

No entanto esta crise, discutida amplamente em redações e salas de aula, não é apenas financeira, ela também é uma crise de credibilidade (Mick, 2017). Leitores, ouvintes e telespectadores já não têm a mesma confiança na mídia. Dentro dessa perspectiva, novos modelos de mídia estão sendo pensados e colocados em prática. $\mathrm{O}$ público também clama por transparência, mas nem sempre as emissoras e grupos de comunicação estão predispostos a desenvolver essa relação honesta com os públicos. Novas iniciativas, como os sites que se mantém com crowdfunding, buscam espaço com contranarrativas, reportagens investigativas, com um viés diferenciado da "grande mídia". Esses sites têm ganhado espaço e respaldo dos públicos, como é o caso da Pública, Agência de Jornalismo Investigativo ${ }^{8}$.

Se vivo fosse, [Perseu certamente estaria orgulhoso, ou até mesmo faria parte], destas iniciativas que, longe do que regem as grandes corporações "com suas poderosas imposições", ajudam a construir um jornalismo que auxilia na construção social da realidade de forma ética e plural, e que, além de informar, ajuda a formar sujeitos críticos.

\section{Referências}

ABRAMO, Perseu. BIONDI, A; CORNILS, P; MORAES, R.; ARBEX JR J.., SOUZA, H. J.; (colaboradores). Padrões de manipulação na grande imprensa. $2^{a}$ edição. São Paulo: Fundação Perseu Abramo, 2016.

Fundação Perseu Abramo. Seção Sobre. Disponível em: https://fpabramo.org.br/2010/02/11/sobre-perseu-abramo/ Acesso em: 13 de janeiro de

8 Pública - Agência de Jornalismo Investigativo - https://apublica.org/. 
2018.

Castells, M. (2003). A galáxia da Internet: reflexões sobre a internet, os negócios e a sociedade. Rio de Janeiro: Jorge Zahar, 2003.

Castells, M. (1999). A Sociedade em Rede (Vol. I, 14ª ed.). São Paulo: Paz e Terra.

MICK, Jacques; TAVARES, Luiza. A governança do jornalismo e alternativas para a crise. Brazilian Journalism Research: journalism theory, research and criticism. vol.13, n. 2, 2017. Disponível em: https://bjr.sbpjor.org.br/bjr/article/download/948/924 Acesso em 20 de novembro de 2018.

PEREIRA FILHO, Francisco José Bicudo. Caros amigos e o resgate da imprensa alternativa no Brasil. São Paulo, Annablume, 2009.

PORTELLA, Laércio. Padrões de manipulação na grande imprensa, um manual para tempos de crise. Marco Zero, 27/05/2016 Disponível em: https://marcozero.org/padroes-de-manipulacao-na-grande-imprensa-um-manualpara-tempos-de-crise/ Acesso em: 10 de janeiro de 2018.

PAULA, Chico de. A visão de Perseu Abramo sobre a manipulação da grande imprensa. Opinião, Revista Carta Capital. 21/02/2014 Disponível em:

<http://biblioo.cartacapital.com.br/a-visao-de-perseu-abramo-sobre-a-manipulacao-dagrande-imprensa/> Acesso em: 10 de janeiro de 2018.

Recebido em: $11 / 06 / 2018$

Publicado em: 21/12/2018 